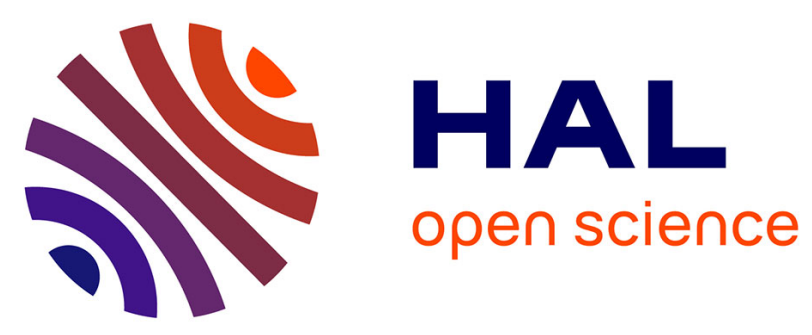

\title{
CORRELATION BETWEEN ELECTRICAL AND VIBRATIONAL PROPERTIES OF CHLORINATED AND HYDROGENATED AMORPHOUS SILICON PREPARED BY GLOW DISCHARGE
}

\author{
S. Al Dallal, Jacques Chevallier, S. Kalem, J. Bourneix
}

\section{To cite this version:}

S. Al Dallal, Jacques Chevallier, S. Kalem, J. Bourneix. CORRELATION BETWEEN ELECTRICAL AND VIBRATIONAL PROPERTIES OF CHLORINATED AND HYDROGENATED AMORPHOUS SILICON PREPARED BY GLOW DISCHARGE. Journal de Physique Colloques, 1982, 43 (C9), pp.C9-323-C9-326. 10.1051/jphyscol:1982960 . jpa-00222489

HAL Id: jpa-00222489 https://hal.science/jpa-00222489

Submitted on 1 Jan 1982

HAL is a multi-disciplinary open access archive for the deposit and dissemination of scientific research documents, whether they are published or not. The documents may come from teaching and research institutions in France or abroad, or from public or private research centers.
L'archive ouverte pluridisciplinaire HAL, est destinée au dépôt et à la diffusion de documents scientifiques de niveau recherche, publiés ou non, émanant des établissements d'enseignement et de recherche français ou étrangers, des laboratoires publics ou privés. 


\title{
CORRELATION BETWEEN ELECTRICAL AND VIBRATIONAL PROPERTIES OF CHLORINAT- ED AND HYDROGENATED AMORPHOUS SILICON PREPARED BY GLOW DISCHARGE
}

\author{
S. Al Dallal, J. Chevallier, S. Kalem and J. Bourneix \\ Laboratoire de Physique des Solides, CNRS, 1, Place A. Briand, 92190 Meudon- \\ Bezzevue, France
}

\begin{abstract}
Résumé. - Des mesures de conductivité électrique et de transmission dans 1'infrarouge ont été effectuées sur des couches de silicium amorphe hydrogéné et chloré préparées par décharge luminescente. En augmentant la puissance délivrée au plasma, nous avons observé un changement dans le mécanisme de transport, accompagné par une évolution des bandes induites par 1 'hydrogène et le chlore. A partir de cette corrélation entre le mécanisme de transport des porteurs de charge et le spectre de transmission dans l infrarouge nous suggérons que 1 'évolution de la concentration d'espèces $\mathrm{SiCl}_{2}$ avec $\mathrm{l}_{\mathrm{a}}$ puissance délivrée au plasma est principalement responsable du changement de densité d'états dans la bande interdite et par conséquent du changement de mécanisme de transport.
\end{abstract}

Abstract. - Electrical conductivity and infrared transmission measurements have been carried out on chlorinated and hydrogenated amorphous silicon films prepared by glow discharge. Upon increasing the plasma power, we observed a change of transport mechanism, accompanied by an evolution of hydrogen and chlorine related bands. From this correlation between the transport and the infrared data we suggest that the evolution of $\mathrm{SiCl}_{2}$ species with the plasma power is mainly responsible for the change in bandgap states density and consequently in the transport mechanism.

INTRODUCTION. - Recently, it has been shown that fluorine, in hydrogenated and fluorinated amorphous silicon, plays the role of a dangling bond terminator as hydrogen does $[1-2]$. Other halogens, such as chlorine, might offer also some interesting possibilities. Until now nothing has been reported about the effect of chlorine on the electrical properties of a-Si : $\mathrm{H}, \mathrm{Cl}$. In previous papers [3] [4]. we have shown that chlorine is able to play the role of a dangling bond terminator in an amorphous silicon matrix. This was deduced from the presence of several new chlorine related bands identified in the infrared absorption spectra [3].

Several authors have reported that the transport properties in a-Si : Hi have a non-monotonic dependence on the hydrogen content [5] [6] since hydrogen may be incorporated in different ways into the material. We shall show that the same argument is true for hydrogen and chlorine in a-Si : H, Cl. Therefore, a direct correlation between the infrared spectra and transport properties provides a better insight into the effect of gap states on the properties of this semiconductor. In this work we used the plasma power as the deposition parameter upon which depend the transport properties. In this approach we shall try first to establish the correlation between the plasma power and the infrared spectra. In a subsequent section, the evolution of the transport properties with plasma power will be investigated. The correlation between the infrared spectra and the transport properties will be discussed finally in the framework of the whole data. 
EXPERIMENTAL PROCEDURE. - Hydrogenated and chlorinated amorphous silicon layers used in this study have been prepared by decomposition of a $\mathrm{SiCl}_{4} / \mathrm{H}_{2} \mathrm{mixture}$ in a R.F. glow discharge onto either Corning glass 7059 substrates for transport studies or crystalline silicon for infrared measurements. The substrates were held at a fixed temperature $\left(\sim 280^{\circ} \mathrm{C}\right)$ and a capacitive system provides the radiofrequency power to the gaseous mixture. The total pressure of the $\mathrm{SiCl}_{4}+\mathrm{H}_{2}$ mixture is maintained at $\mathrm{O}, 5$ torr and the partial pressure ratio $\mathrm{P}\left(\mathrm{SiCl}_{4}\right) / \mathrm{P}\left(\mathrm{H}_{2}\right)$ is $1 / 8$. The gas flow is typically of the order of $8 \mathrm{scc} / \mathrm{s}$. Under these conditions the growth rate is about 3 to $8 \AA / s$.

CHLORINE AND HYDROGEN CONCENTRATIONS. - The chlorine content in our samples has been measured by electron microprobe analysis. Typical concentration of chlorine is approximately $6 \%$ at. for all the samples. The distribution of chlorine is homogeneous on the surface. From SIMS investigations, we concluded that the chlorine content was constant along the thickness of the layer. On the other hand, the concentration of oxygen is less than $0,5 \%$. However, undeliberately oxygenated samples (few percent oxygen) have been investigated and will be included in the transport data.

The hydrogen content in our samples was calculated by integrating the $i . r$. band at $640 \mathrm{~cm}^{-1}$. The amount of hydrogen estimated by this method is $6 \%$ at. in samples prepared at low plasma power ( 5 watts) and increases up to $12 \%$ at. in samples prepared at high plasma power ( 40 watts). The total quantity of hydrogen has also been measured by nuclear reaction method. We found $6 \%$ at. of hydrogen in samples prepared at 5 watts and this quantity increases up to $11 \%$ at. of hydrogen in those prepared at 40 watts. These results are in very good agreement with those obtained by integrating the infrared absorption band at $640 \mathrm{~cm}^{-1}$.

\section{EVOLUTION OF THE HYDROGEN AND CHLORINE RELATED VIBRATIONAL MODES WITH PLASMA POWER.}

We have studied the evolution of the infrared vibrational spectra in samples prepared at different plasma powers. Fig. (1) shows typical spectra for samples

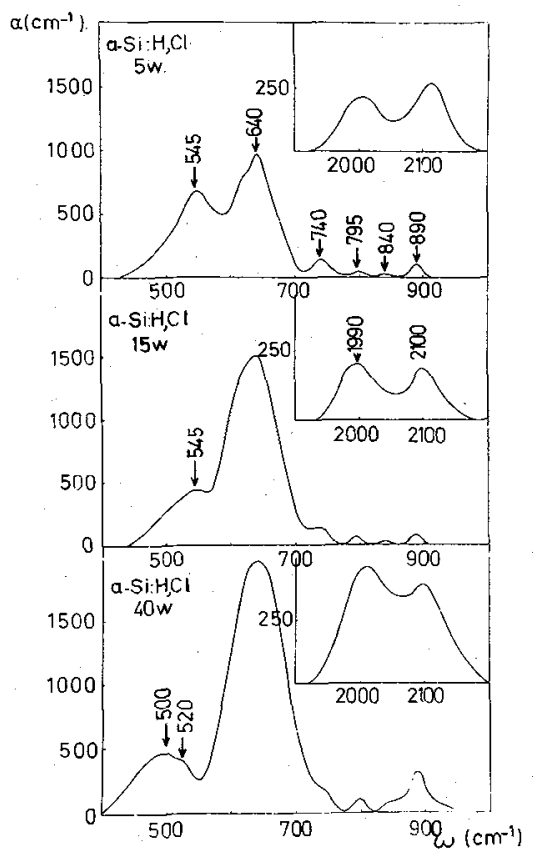
prepared at 5,15 and 40 watts in the 200 $4000 \mathrm{~cm}^{-1}$ region. In a previous paper [3], we established that samples prepared at low plasma power exhibit infrared transmission spectra containing several bands corresponding either to $\mathrm{SiH}$ or to Sicl vibrational modes. Referring to infrared studies in a-SiH $[7]$, we attributed the 1990 and $2110 \mathrm{~cm}^{-1}$ bands respectively to the stretching modes of $\mathrm{SiH}$ and $\mathrm{SiH}_{2}$ groups, the 890 and $840 \mathrm{~cm}^{-1}$ bands to bending modes of $\mathrm{SiH}_{2}$ and ( $\left.\mathrm{SiH}_{2}\right)_{\mathrm{n}}$ groups and the $640 \mathrm{~cm}^{-1}$ band to the wagging-rocking modes of $\mathrm{SiH}$ and $\mathrm{SiH}_{2}$ species. With respect to purely hydrogenated amorphous silicon, the infrared spectra of our low power chlorinated samples contain several new infrared bands at 500, 545,740,795 $\mathrm{cm}^{-1}$ and another one in the $610 \mathrm{~cm}^{-1}$ region Basing our approach of the identification of the 545 and $610 \mathrm{~cm}^{-1}$ bands on the correlation between the stretching mode frequency of SiCl bonds and the substituted group electronegativity and also on a theoretical approach of the calculated vibrational frequencies of various silicon-halogen groups [8], we attribute these two bands to the symmetric and asymmetric stretching vibrational modes of $\mathrm{SiCl}_{2}$ types of configurations, either isolated or in chains. However, we do not exclude the possible contribution of the stretching modes of SiCl bonds in $\operatorname{SiCl}_{y}\left(\mathrm{H}_{x}\right)$ configurations to the Fig. 1 : Evolution of the I.R.absor-band at $545 \mathrm{~cm}^{-1}$. Replacing hydrogen by deuteption spectra versus theplasma powerrium, we have shown elsewhere that the 740 and 
$795 \mathrm{~cm}^{-1}$ are silicon-hydrogen related vibrational bands in $\mathrm{H}_{\mathrm{X}} \mathrm{SiCl} \mathrm{y}$ species where hydrogen and chlorine are attached to the same silicon atom [8].The $500 \mathrm{~cm}^{-1}$ tail has been assigned to a chlorine induced To optical phonon of the amorphous silicon matrix. Infrared measurements carried out on a large number of samples prepared at increasing power from 5 to 40 watts show : an increase of the $640 \mathrm{~cm}^{-1}$ and $1990 \mathrm{~cm}^{-1}$ band intensities, no significant variation of the 840,740 and $795 \mathrm{~cm}^{-1}$ band intensities, a relative dispersion in the intensity of the $2100 \mathrm{~cm}^{-1}$ and $890 \mathrm{~cm}^{-1}$ band intensities around an average value, a decrease in the intensity of the $545 \mathrm{~cm}^{-1}$ and $610 \mathrm{~cm}^{-1}$ bands. At 40 . watts, these bands disappear and are replaced by a band at $500 \mathrm{~cm}^{-1}$ with a shoulder at $520 \mathrm{~cm}^{-1}$. A detailed analysis of the infrared spectra in the $500-520 \mathrm{~cm}^{-1}$ region is difficult because of the close proximity of the matrix phonon bands. However, the shoulder at $520 \mathrm{~cm}^{-1}$ might be associated to the stretching mode of Sic1 in some configuration other than $\mathrm{SiCl}_{2}$.

ELECTRICAL CONDUCTIVITY. - We carried out a series of conductivity measurements as a function of temperature on various films deposited at different plasma power. In Fig. (2) we show the temperature dependence of the electrical conductivity in the range $260 \mathrm{~K}-300 \mathrm{~K}$ for three films deposited at 10 watts. These samples are characterized by two activation energies. The high activation energy $(0,8-0,9 \mathrm{eV}$ for $\mathrm{T}>260 \mathrm{~K})$ corresponds to transport of carriers in extended states above the mobility edge 59$]$ [10]. Below $265 \mathrm{~K}$, the activation energy is slightly reduced $(0.7-0.8 \mathrm{eV})$. The conduction: process in this region corresponds to variable range hopping of carriers in the conduction band tail states [9][11]. Fig. (3) shows a series of $10 \mathrm{~g} \sigma$. versus $10^{3} / \mathrm{T}$ curves in the temperature range $260 \mathrm{~K}$ - 300K for samples prepared at a plasma power of 5 watts. The conductivity here is an activated process with a
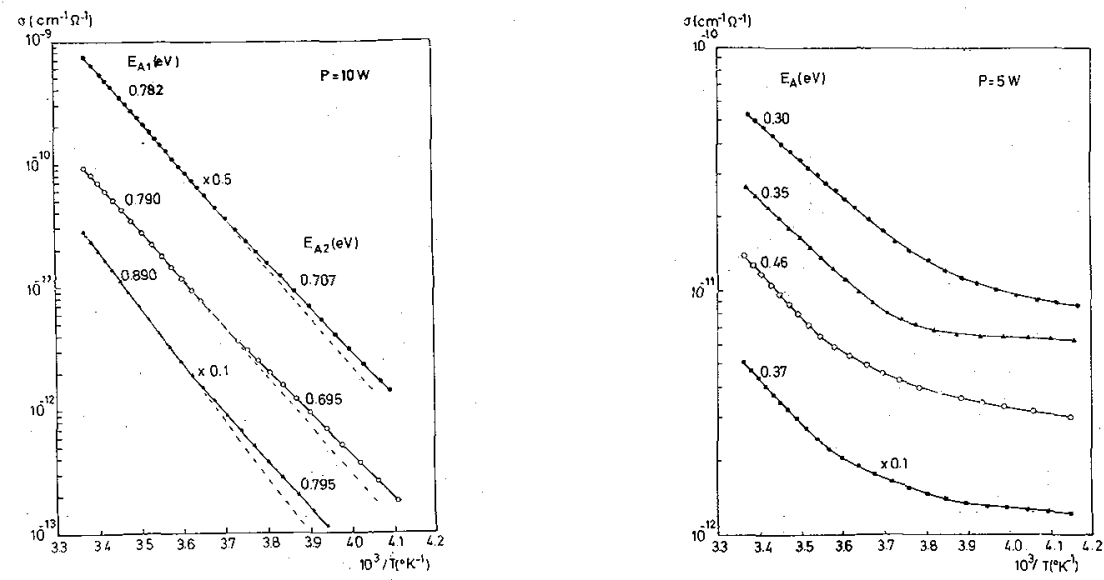

Fig.2: Temperature dependence of the elec- Fig.3: Temperature dependence of the electrical conduc tivity for samples prepared at 10 Watts. trical corductivity for samples prepared at $5 \mathrm{Wat}$ ts.

relatively low activation energy $(0.3-0.4 \mathrm{eV})$. At lower temperatures the curves level out gradually and can no longer be described by a simple activated process. The low value of the activation energy is significant of transport of carriers by hopping in the band gap states [10]. The results are summarized in Fig. (4) in which we show the electrical conductivity $\sigma(\mathrm{at} 300 \mathrm{~K})$, the activation energy $\mathrm{E}_{\mathrm{A}}$ in the room temperature region, and the preexponential factor $\sigma_{\circ}$ as a function of the plasma power. Fig. (4) also includes results of a $\mathrm{Wi}: \mathrm{H}, \mathrm{Cl}$ samples containing oxygen (open circles). From this figure we notice an increase in the value of the room temperature conductivity as well as the activation energy (in the $300 \mathrm{~K}-260 \mathrm{~K}$ range) as the R.F. power delivered to the plasma increases from 5 to 10 watts. An important feature of this figure is the abrupt change in the preexponential factor $\sigma_{0}$ between 5 and 10 watts A similar behaviour of the freexponential factor has been reported by Le Comber et al 99$]$ in a-SiH. These authors have observed a drop in oo by a factor of $10^{6}$ when the substrate temperature is brought up to a critical value ( $350 \mathrm{~K}$ ). In our case, typical values of $\sigma_{0}$ and $E$. for samples prepared at 5 watts are $10^{-4} \Omega^{-1} \mathrm{~cm}^{-1}$ and $0.35 \mathrm{eV}$ respectively? As alleady discussed, these values are more significant of a 


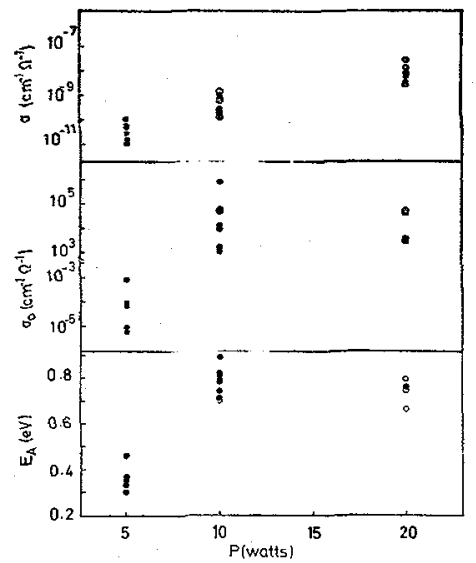

Fig. 4 : Evolution of parameters $\sigma, \sigma$ and $E_{A}$ as a function of the plasma power. conduction in localized states at room temperature For samples prepared at $\mathrm{P}>10$ watts, typical values of $\sigma_{0}\left(10^{4} \Omega^{-1} \mathrm{~cm}^{-1}\right)$ and $E_{A}(0.8 \mathrm{eV})$ are more indicative of a conduction of carriers in extended states above the mobility edge $[10]$ at $300 \mathrm{~K}$.

DISCUSSION. - The transport results show that there is a notable improvement of the electronic quality of the material, accompanied by an evolution of the intensity of the different hydrogen and chlorine related vibrationalbands. In a-Si:H, the Xerox group found a relationship between the spin concentration and the amount of $\mathrm{SiH}_{2}$ in form of isolated species and in chains [12][13]. Our material contains $1.5 .10^{17} \mathrm{~cm}^{-3}$ spins whatever the plasma power is. Moreover, the $\mathrm{SiH}_{2}$ bands intensity varies around an average value as the power increases and no correlation exists between the $\mathrm{SiH}_{2}$ amount and the transport properties. So, we suggest that the $\mathrm{SiH}_{2}$ species are not the dominant contribution giving $r$ ise to band gap states. As shown in infrared data, the $740 \mathrm{~cm}^{-1}$ and $795 \mathrm{~cm}^{-1}$ bands induced by $\mathrm{H}_{\mathrm{x}} \mathrm{SiCl}$ y configurations are almost independent of the flasma power. Therefore, these species are not either directly responsible for the change in the transport mechanism. The most significant change in our infrared transmission spectra concerns the disappearance of the 545 and $610 \mathrm{~cm}^{-1}$ bands, main $1 \mathrm{y}$ related to $\mathrm{SiCl}_{2}$ configurations, as the plasma power increases. We conclude that the change in the transport mechanism results from a variation in defect states concentration connected with the presence of $\mathrm{SiCl}_{2}$. Such an explanation should be confinmed by calculations of energy levels position. In fact, calculation of state levels in a-Si : H, F by OLCAO method have shown that $\mathrm{SiF}_{3}$ configurations give rise to gap states 「14] whereas configurations such as SiFH, SiFHH, SiFF and SiFFH do not introduce additionnal states in the band gap. It would be useful to develop such a calculation in the case of a-Si : $\mathrm{H}, \mathrm{Cl}$ in order to see how it compares with our experimental data and with theoretical predictions on a-Si : H,F.

AGKNOWLEDGMENTS. - The authors wish to thank Dr TOULENGNDE, Centre de Recherches Nucléaires, STRASBOURG, for the total hydrogen amount determination ty nuclear activation method. They would also thank Mrs M. ROMMELUERE for the chlorine concentration measurements by electron microprobe analysis.

REFERENCES. -

[1] MATSUMURA H., NAKAGOME Y., FURUFAWA S., App1. Phys. Lett. 36, 6 (1980) 439.

「2] FANG C. ., LEY L., SHANKS HR., GRUNTZ J.,CARDONA M., Phys. ReV•B 22, 12 (1980) 6140.

「3] KALEM S., CHEVALLIER J., AL DALLAL S., BOURNEIX J, J.Phys., Goll. C4 supp1. nº 10, 42(1981) 361 .

[4] CHEVALLIER J., KALEM S., AL DALlial S., BOURNEIX J., J.Non Cryst.Sol. (to be pubi.).

[5] ANDERSON D.A.;MCUSTAKAS.T.D. and PAUL W., Proc. 7 th Intern. Conf. on Amorphous and Liquid Semicond., edited by W.E.Spear (1977) 334 .

[6] FREEMAN E.C. and PAUL W., Phys. Rev. B, 18(1978) 4288.

[7] BRODSKY M.H., CARDONA M., CUOMO J.J., Phys. Rev. B, 16 (1977) 3556.

[8] GHEVALLIER J., KALEM $\varsigma_{.}$, BOURNEIX J., VANDEVYVER $M_{\bullet}$, to be publ, in the Proceedings of the 16th Intern. Conf. on the Physics of Semiconductors (1982).

[9] Le COMBER P.G.,MADAN A. and SPEAR W.E., J. Non Cryst.So1.11, (1972) 219.

[10] MOTT N.F. and DAVIS E.A.,Electronic Processes in Non Cryst.Mat..(2nd Ed.) Clarendon Press, Oxford (1979).

[11] GRANT A.J. and DAVIS E.A.,, Sol. State Ccmm. 15 (1974) 563.

[12] STREET R.A., KNIGHTS J.C. and BIEGELSEN D.K.,Phys. Rev • B, 18 (1978) 1880.

[13]LUCOVSKY G., NEMANICH R.J. and KNIGHTS J.C.,Phys. Rev. B, 19 (1979) 2064.

[14]GHING W.Y., J. Non Cryst. Solids, 35_\&_36 (1980) 61-66. 